\title{
Timing in analytical pyrolysis: Py(HMDS)-GC/MS of glucose and cellulose using on-line micro reaction sampler
}

\author{
Marco Mattonai, Diego Tamburini, Maria P. Colombini, Erika Ribechini* \\ Department of Chemistry and Industrial Chemistry, University of Pisa, via Giuseppe Moruzzi 13, I-56124, Pisa, Italy
}

\begin{abstract}
A novel analytical approach based on pyrolysis-gas chromatography coupled with mass spectrometry with in situ silylation using hexamethyldisilazane for the study of carbohydrates is presented in this work for the first time. A micro reaction sampler was used to simultaneously obtain the pyrolyis reaction and facilitate the derivatisation of pyrolysis products of glucose and cellulose, by enabling the materials to react with the derivatising agent in a sealed capsule at high temperatures and for long periods of time. This drastically increased the complete silylation of the pyrolysis products and reduced the complexity of the pyrograms obtained compared to fast pyrolysis. In particular, the partial silylation of anhydrosugars, among the main pyrolysis products, was almost completely overcome after ten minutes of reactive pyrolysis. Different results were also obtained for glucose and cellulose in terms of predominant pyrolytic pathways. The formation of anhydrosugars, in particular levoglucosan, was the preferential pyrolytic reaction for glucose. The formation of cyclopentenones and small fragmented molecules with up to three carbon atoms was predominant for the pyrolysis of cellulose in the adopted conditions. This work discloses a powerful and potentially widely applicable analytical method for the investigations of organic materials under controlled pyrolytic conditions with the advantage of increasing the effectiveness of in situ derivatisation.
\end{abstract}

The study of carbohydrates and of their reactivity is a subject of high interest in several fields of scientific research, such as food, renewable energy, biopolymers, pharmacy, etc. A wide variety of analytical techniques have been developed and optimised to investigate different properties of both simple and complex carbohydrates ${ }^{1-7}$.

Analytical pyrolysis is a powerful technique for the analysis of polymeric materials, and it has been widely used to study cellulose in detail since the ' $70 \mathrm{~s}^{8-11}$. Pouwels et al. reported an exhaustive description of the pyrolysis products obtained from micro-crystalline cellulose using Curie-point pyrolysis ${ }^{9}$. Analytical pyrolysis allows the thermal breakdown of a macromolecule into smaller molecules, which can be analysed by gas chromatography, thus providing a specific fingerprint of the original material and information at a molecular level ${ }^{12}$. Analytical pyrolysis has also been effectively used to understand the decomposition pathway of lignocellulosic materials, as well as the effects of catalysts during pyrolysis ${ }^{13-15}$.

The pyrolysis of simple and complex carbohydrates leads to the formation of many pyrolysis products bearing hydroxyl functional groups. Such compounds, being highly polar, are not suitable for gas chromatographic analysis, and can cause peak broadening with a loss in resolution due to detrimental column adsorptions as well as adsorption at the Py-GC interface. A derivatisation step is therefore recommended, and the most common derivatisation reactions are methylation and silylation ${ }^{16-18}$. TMAH (tetramethylammonium hydroxide) is the most common methylating agent, but its use leads to the occurrence of racemisation and reduction reactions, the creation of a strong alkaline environment, and the production of noninformative products ${ }^{18}$. Moldoveanu ${ }^{8}$ and Fabbri et al. ${ }^{17,19,20}$ applied silylation as derivatisation reaction. Off-line and online procedures were tested using different silylating agents, such as hexamethyldisilazane (HMDS), trimethylsilyldiethylamine (TMSDEA), bis(trimethylsilyl)trifluoroacetamide (BSTFA) and trimethylsilylimidazole (TMSI) ${ }^{19}$. The in situ addition of HMDS during on-line pyrolysis was found to be a powerful method for the characterisation of cellulose ${ }^{17}$, also in complex matrices such as wood ${ }^{21-23}$. The main drawback is the formation of partially silylated pyrolysis products, in particular anhydrosugars, since the short time of pyrolysis (less than one minute) and the steric hindrance effects do not allow a sufficient contact time between the pyrolysis products and the derivatising agent 17,19-21. All this greatly increases the complexity of the pyrograms.

With the aim to overcome the phenomenon of partial silylation, we investigated the potentialities of the micro reaction sampler. As described by Hosoka et al. ${ }^{24}$, such pyrolysis accessory was developed to make easier the analysis of intractable and high molecular weight polymers, since the reaction occurs at an elevated temperature in a sealed glass capsule under high pressure for a selected time. The authors used the micro reaction sampler for the study of polycarbonate and nylon 6.6, using tetramethylammonium hydroxide as derivatising agent. Fu et al. ${ }^{25}$ applied the micro reaction sampler to the study of lignin pyrolysis, although they did not focus on the effect of pyrolysis time on the composition of pyrolysis products. At the best of our knowledge, our work represents the first investigation of the potentiality of this technique with application to carbohydrates and using HMDS. 


\section{EXPERIMENTAL SECTION}

Materials. D-(+)-glucose (99.5\%), Sigmacell cellulose type 101 and hexamethyldisilazane $(99.9 \%)$ were purchased from Sigma-Aldrich (USA). The presence of inorganics in cellulose was evaluated by heating $1 \mathrm{mg}$ of sample in a muffle furnace at $700{ }^{\circ} \mathrm{C}$ for $2 \mathrm{~h}$. No solid residue was found.

Py-GC/MS Apparatus. The instrumentation consisted of a micro-furnace pyrolyzer EGA/PY-3030D (Frontier Lab, Japan) connected to a 6890 gas chromatograph equipped with a split/splitless injector. The gas chromatograph was coupled with a 5973 Mass Selective Detector (Agilent Technologies, USA). A PY1-1050 Micro Reaction Sampler was used as a sample holder in all experiments. The two main elements of this sampler are the pyrolysis chamber and the crushing rod, as illustrated by Hosaka et al. ${ }^{24}$

The pyrolysis chamber holds a glass capsule containing the sample, which is initially lowered into the furnace, where the pyrolysis takes place at the set temperature and reaction time. During the pyrolysis, the products are trapped inside the capsule. After the set amount of time has elapsed, the rod is lowered using the rotating knob, crushing the capsule and sending the pyrolysis products to the chromatographic system.

When performing experiments with the reactive sampler, a metal pyrolysis tube must be used in place of the usual quartz one inside the furnace, in order to withstand the pressure spike arising when the capsule is crushed. The use of a glass capsule to hold the sample allows pyrolysis temperatures up to $400{ }^{\circ} \mathrm{C}$ to be employed.

Sample Preparation. Approximately $100 \mu \mathrm{g}$ of glucose or cellulose were weighted directly inside the capsule, and $3 \mu \mathrm{L}$ of the derivatising agent (hexamethyldisilazane) were added. The capsule was then put under a gentle stream of nitrogen to ensure an inert atmosphere, and finally it was flame-sealed and inserted in the pyrolysis chamber.

Experimental Parameters. Pyrolysis was performed in all experiments with a furnace temperature of $400{ }^{\circ} \mathrm{C}$ and an interface temperature of $280{ }^{\circ} \mathrm{C}$. Pyrolysis products were injected in the chromatographic system with a 20:1 split ratio and at a temperature of $280{ }^{\circ} \mathrm{C}$. Chromatographic separation was obtained using an HP 5MS column $(30 \mathrm{~m} \times 0.25 \mathrm{~mm}$, film thickness $0.25 \mu \mathrm{m}$, Agilent Technologies, USA) coupled with a deactivated silica pre-column ( $2 \mathrm{~m} \mathrm{x} 0.32 \mathrm{~mm}$, Agilent Technologies, USA) and helium as carrier gas $(1 \mathrm{~mL} / \mathrm{min})$. A temperature program was used for the chromatographic oven: $50{ }^{\circ} \mathrm{C}$ isothermal for $1 \mathrm{~min}, 10{ }^{\circ} \mathrm{C} / \mathrm{min}$ up to $100{ }^{\circ} \mathrm{C}, 100{ }^{\circ} \mathrm{C}$ isothermal for $2 \mathrm{~min}, 4{ }^{\circ} \mathrm{C} / \mathrm{min}$ up to $190{ }^{\circ} \mathrm{C}, 190{ }^{\circ} \mathrm{C}$ isothermal for $1 \mathrm{~min}, 30{ }^{\circ} \mathrm{C} / \mathrm{min}$ up to $280{ }^{\circ} \mathrm{C}, 280{ }^{\circ} \mathrm{C}$ isothermal for 30 min. The mass spectrometer was operated in EI positive mode (70 eV, $\mathrm{m} / \mathrm{z}$ range $50-600)$. The transfer line was kept at 300 ${ }^{\circ} \mathrm{C}$, while the ion source was kept at $230{ }^{\circ} \mathrm{C}$ and the quadrupole at $150{ }^{\circ} \mathrm{C}$.

The reaction times for pyrolysis experiments were $0.2,0.5$, $1,2,5,10,20,30$ and 60 minutes for both glucose and cellulose.

Data Interpretation. Pyrograms were analysed using the Automated Mass spectra Deconvolution and Identification
System by NIST (AMDIS, version 2.71). Pyrolysis products were identified by comparison with previous results in the literature $e^{9,20,21,26-28}$, and by match with mass spectra from the Wiley and NIST/EPA/NIH spectral libraries. Some attempts were also made at identifying previously unreported species. Semi-quantitative calculations were performed: percentage areas were calculated for each pyrolysis product, considering the sum of all the compounds integrated. The values were used to compare and interpret the results, as discussed below. To evaluate the reproducibility, pyrolysis experiments were performed in triplicate at 0.5 and 30 minutes. The relative standard deviations obtained for all the calculations performed were $\leq 10 \%$, thus showing a good reproducibility of the technique.

\section{RESULTS AND DISCUSSION}

Glucose. Figure 1 presents the pyrograms obtained for 0.5 and 30 minutes pyrolysis time, representative of a relatively short and long pyrolysis/reaction time, respectively. The peaks corresponding to identified compounds are labelled with a number, and a complete list is reported in Table 1. The molecular structures of some compounds were not disclosed. Nevertheless, these pyrolysis products are included in Table 1 for completeness of information. All the reported species were also divided into categories according to their molecular structures and pyrolytic formation.

The pyrolytic profile of glucose showed remarkable changes depending on the pyrolysis time. The pyrograms obtained for short pyrolysis times $(0.2,0.5$ and $1 \mathrm{~min})$ were very similar. The most abundant pyrolysis products were 1,6-anhydro- $\beta$-Dglucopyranose-2TMS (\#57) and 1,6-anhydro- $\beta$-Dglucofuranose-3TMS (\#65). These two anhydrosugars are reported as the most abundant pyrolysis products of glucose, since they are produced by elimination of one water molecule, which is considered one of the initial and predominant pyrolysis reactions of monosaccharides ${ }^{29}$. In addition to these major pyrolysis products, some small molecules, such as hydroxyacetic acid (\#7) and dihydroxyacetone (\#25) showed relatively high abundances. The formation of such pyrolysis products takes place from a variety of reactions including eliminations, fragmentation, extrusions, and rearrangements 30,31. 5hydroxymethyl-2-furaldehyde (\#31) was also detected among the most abundant pyrolysis products. In fact, furan derivatives (five-ring cycle containing one oxygen) are also common pyrolysis products of glucose ${ }^{32}$.

The results are comparable to those obtained with conventional flash pyrolysis, since the pyrolysis and derivatisation reactions occur very rapidly and can be considered simultaneous. As a consequence, the formation of partially silylated pyrolysis products, especially anhydrosugars, is a significant collateral effect. In fact, mono-TMS (\#47, 48) and bis-TMS (\#52, 53, 55 and 57) anhydrosugars are present with high relative abundances in the pyrograms of glucose at short pyrolysis times, compared to the corresponding tri-TMS compounds (\#63, 64, 65). 


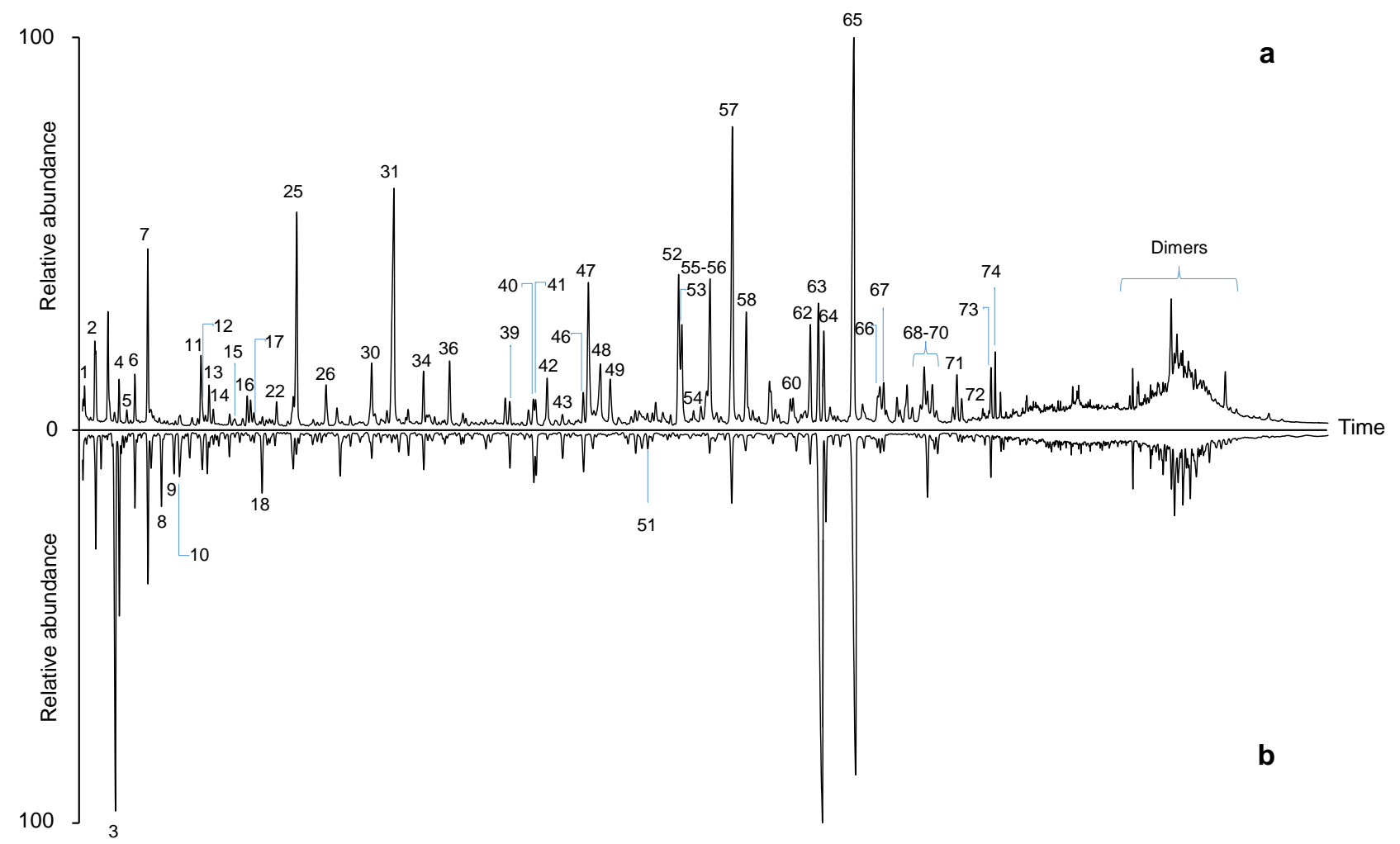

Figure 1. Pyrograms of glucose obtained by Py(HMDS)-GC/MS using pyrolysis times of a) 0.5 minutes and b) 30 minutes.

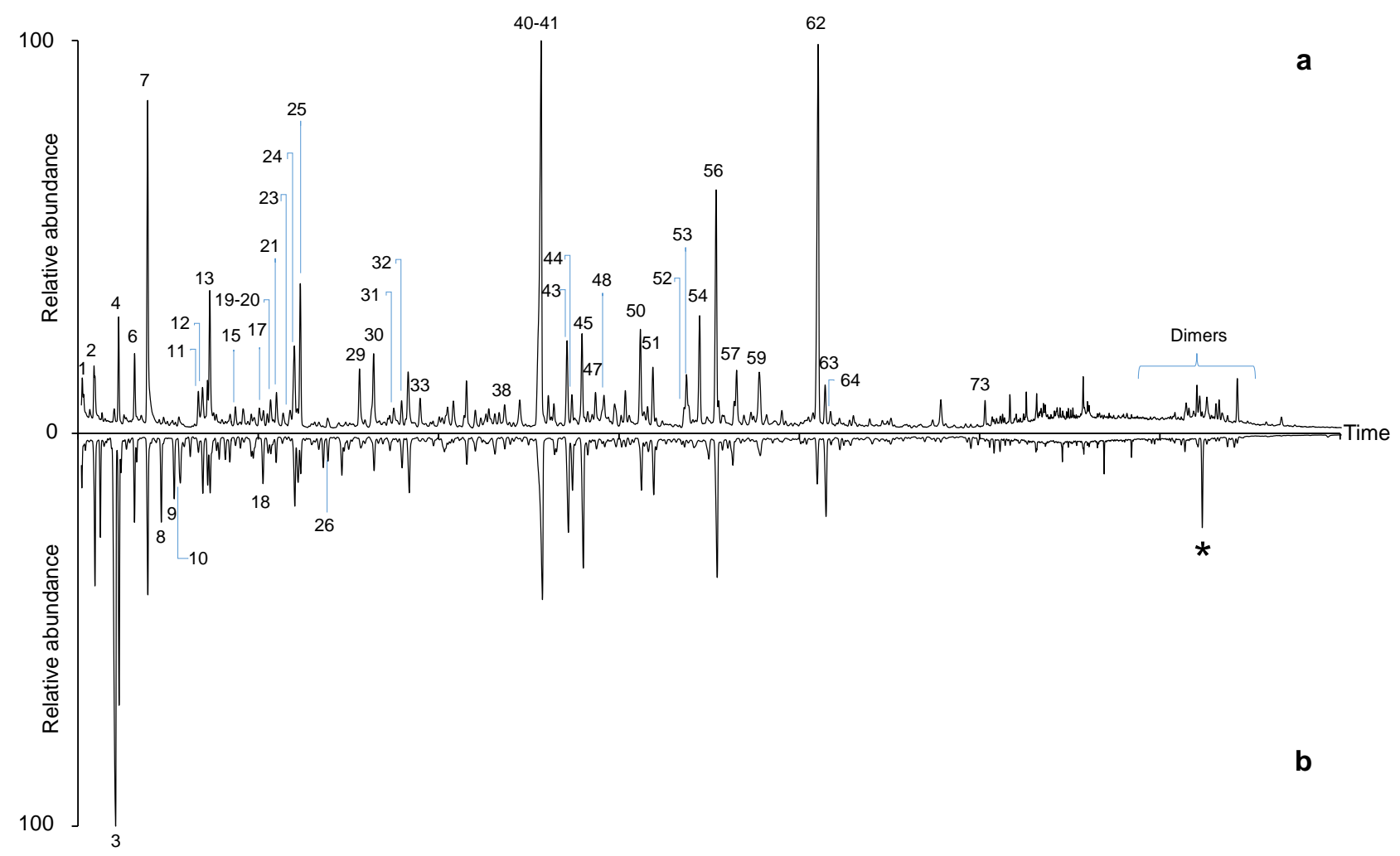

Figure 2. Pyrograms of cellulose obtained by Py(HMDS)-GC/MS using pyrolysis times of a) 0.5 minutes and b) 30 minutes. 
Table 1. List of pyrolysis products identified in the pyrograms of glucose and cellulose. Numbers refer to the peak numbers in the pyrograms shown in Figures 1 and 2.

\begin{tabular}{|c|c|c|c|c|}
\hline $\mathbf{N}^{\circ}$ & Compounds & TMS $^{\text {a }}$ & Most abundant $\mathbf{m} / \mathbf{z}$ & Compound class \\
\hline 1 & 2-hydroxymethylfuran & 1 & $75,81,111,125,142,155,170$ & Furans \\
\hline 2 & hydroxyacetaldehyde, enolic form & 2 & $73,147,189,204$ & Small molecules \\
\hline 3 & hydroxyacetone, enolic form I & 2 & $73,100,147,188,203$ & Small molecules \\
\hline 4 & silane I & - & $73,191,207,295$ & - \\
\hline 5 & phenol (G) & 1 & $73,151,166$ & Aromatics \\
\hline 6 & silane II & - & $73,117,147,191,207,295$ & - \\
\hline 7 & hydroxyacetic acid & 2 & $73,133,147,161,177,205$ & Small molecules \\
\hline 8 & pyruvic acid, enolic form I & 2 & $73,100,114,128,147,217$ & Small molecules \\
\hline 9 & hydroxyacetone, enolic form II & 2 & $73,100,116,147,188,203$ & Small molecules \\
\hline 10 & 3-oxopropanoic acid, enolic form I & 2 & $73,114,129,147,191,217$ & Small molecules \\
\hline 11 & 2-furancarboxylic acid & 1 & $73,95,125,169,184$ & Furans \\
\hline 12 & unknown I & - & $73,152,167$ & Others \\
\hline 13 & 1,2-cyclopentadione, enolic & 1 & $73,75,81,111,155$ & Cyclopentenones \\
\hline 14 & 3-hydroxypropanoic acid (G) & 2 & $73,147,177,219$ & Small molecules \\
\hline 15 & unknown II & - & $85,101,115,131,159$ & Others \\
\hline 16 & 3-hydroxycyclopenta-1,2-dione (G) & 1 & $73,115,129,143,171,186$ & Cyclopentenones \\
\hline 17 & 2-hydroxycyclopenta-1,3-dione & 1 & $73,75,101,143,171$ & Cyclopentenones \\
\hline 18 & unknown III & - & $73,104,116,147,188,204$ & Others \\
\hline 19 & 1,2-dihydroxybenzene (C) & 1 & $75,91,136,151,167,182$ & Aromatics \\
\hline 20 & 3-hydroxy $(4 \mathrm{H})$ pyran-4-one $(\mathrm{C})$ & 1 & $75,95,147,169,184$ & Pyrans \\
\hline 21 & 5-hydroxy-2H-pyran-4(3H)-one $(\mathrm{C})$ & 1 & $73,75,101,129,143,171,186$ & Pyrans \\
\hline 22 & 2-hydroxymethyl-3-methylcyclopenten-2-one (G) & 1 & $73,117,147,183,198$ & Cyclopentenones \\
\hline 23 & 2-methylcyclopenta-1,3-dione, enolic form (C) & 1 & $75,117,139,169,184$ & Cyclopentenones \\
\hline 24 & 3-methylcyclopenta-1,2-dione, enolic form (C) & 1 & $73,97,169,184$ & Cyclopentenones \\
\hline 25 & dihydroxyacetone & 2 & $73,103,129,147,189,219$ & Small molecules \\
\hline 26 & unknown IV & - & $73,217,232$ & Others \\
\hline 27 & 3-hydroxy-6-methyl-(2H)-pyran-2-one (G) & 1 & $75,109,139,168,183,198$ & Pyrans \\
\hline 28 & glycerol & 3 & $73,103,117,133,147,205,218$ & Small molecules \\
\hline 29 & 2-methyl-3-hydroxymethyl-2-cyclopentenone & 1 & $73,103,129,153,183,198$ & Cyclopentenones \\
\hline 30 & 2,3-dihydrofuran-2,3-diol & 2 & $73,147,157,231,246$ & Furans \\
\hline 31 & 5-hydroxymethyl-2-furaldehyde & 1 & $73,109,139,169,183,198$ & Furans \\
\hline 32 & 1,2-dihydroxybenzene $(\mathrm{C})$ & 2 & $73,239,254$ & Aromatics \\
\hline 33 & 3-hydroxycyclopenta-1,2-dione, enolic form (C) & 2 & $73,133,147,169,230,243,258$ & Cyclopentenones \\
\hline 34 & 2,3-dihydroxypropanoic acid $(\mathrm{G})$ & 3 & $73,103,117,133,147,189,205,292,307$ & Small molecules \\
\hline 35 & $1,4: 3,6$-dianhydro- $\alpha$-D-glucopyranose & 1 & $59,69,73,81,85,103,117,129,145,155,170$ & Anhydrosugars \\
\hline 36 & unknown V $(\mathrm{G})$ & - & $73,103,117,129,133,147,189,231$ & Others \\
\hline 37 & 1,4-dihydroxybenzene & 2 & $73,239,254$ & Aromatics \\
\hline 38 & Arabinofuranose $(\mathrm{C})$ & 4 & $73,103,129,143,147,217,230$ & Others \\
\hline 39 & 2-(1,2-dihydroxyethyl)-furan $(G)$ & 2 & $73,147,169,183,257,272$ & Furans \\
\hline 40 & 3-hydroxy-2-hydroxymethyl-2-cyclopentenone & 2 & $73,257,272$ & Cyclopentenones \\
\hline 41 & 2-hydroxycyclopenta-1,3-dione, enolic form & 2 & $73,133,147,243,258$ & Cyclopentenones \\
\hline 42 & 3,5-dihydroxy-2-methyldihydro(4H)pyran-4-one $(\mathrm{G})$ & 2 & $73,101,147,155,183,273,288$ & Pyrans \\
\hline 43 & 3-hydroxy-2-hydroxymethylcyclopenta-2,4-dienone & 2 & $73,147,255,270$ & Cyclopentenones \\
\hline 44 & 1,2,5-trihydroxypentane $(\mathrm{C})$ & 3 & $73,85,133,143,147,233$ & Aromatics \\
\hline 45 & unknown VI (C) & - & $73,133,147,231$ & Others \\
\hline 46 & 3,5-dihydroxy-2-methyl(4H)pyran-4-one & 2 & $73,128,199,271,286$ & Pyrans \\
\hline 47 & 1,6 -anhydro- $\beta$-D-glucopyranose $(\mathrm{C} 4)$ & 1 & $73,103,117,129,145,155,171$ & Anhydrosugars \\
\hline 48 & 1,6 -anhydro- $\beta$-D-glucopyranose (C2) & 1 & $73,101,116,129,145,155$ & Anhydrosugars \\
\hline 49 & 2-deoxy-D-ribono-1,4-lactone $(\mathrm{G})$ & 2 & $73,97,103,147,189,219,261$ & Lactones \\
\hline 50 & 2-methyl-3-hydroxycyclopentanone, enolic form (C) & 2 & $73,103,147,169,185,243,258$ & Cyclopentenones \\
\hline 51 & 1,2,3-trihydroxybenzene & 3 & $73,239,342$ & Aromatics \\
\hline 52 & 1,4 -anhydro-D-galactopyranose & 2 & $73,101,116,129,145,155,189,204,217$ & Anhydrosugars \\
\hline 53 & 1,6-anhydro-D-galactopyranose & 2 & $73,101,116,129,145,161,189,204,217$ & Anhydrosugars \\
\hline 54 & 2-hydroxymethyl-5-hydroxy-2,3-dihydro(4H)pyran-4-one & 2 & $73,129,147,155,183,273,288$ & Pyrans \\
\hline 55 & 1,4-anhydro-D-glucopyranose & 2 & $73,129,157,191,217$ & Anhydrosugars \\
\hline 56 & $1,2,4$-trihydroxybenzene & 3 & $73,239,342$ & Aromatics \\
\hline 57 & 1,6 -anhydro- $\beta$-D-glucopyranose & 2 & $73,101,116,129,155,191,204,217,230$ & Anhydrosugars \\
\hline 58 & xyloic acid $\gamma$-lactone $(\mathrm{G})$ & 3 & $73,103,117,147,189,204,217,231,246,259,349,364$ & Lactones \\
\hline 59 & 4,5-dihydroxy-2-hydroxymethyl-(2H)-pyrane (C) & 3 & $73,103,133,147,257,330,345,360$ & Pyrans \\
\hline 60 & 2,3-dihydroxy-6-methyl-(4H)-pyran-4-one $(\mathrm{G})$ & 2 & $73,147,169,271,286$ & Pyrans \\
\hline 61 & unknown VII & - & $73,103,129,191,204,217,243,333$ & Others- \\
\hline 62 & 2,3,5-trihydroxy(4H)pyran-4-one & 3 & $73,103,133,147,255,330,345,360$ & Pyrans \\
\hline 63 & 1,6 -anhydro- $\beta$-D-glucopyranose & 3 & $73,103,129,147,191,204,217,243,333$ & Anhydrosugars \\
\hline 64 & 1,4 -anhydro- $\beta$-D-glucopyranose & 3 & $73,103,117,129,147,191,204,217,243,332$ & Anhydrosugars \\
\hline 65 & 1,6 -anhydro- $\beta$-D-glucofuranose & 3 & $73,101,116,129,147,157,191,217,243,319$ & Anhydrosugars \\
\hline 66 & riboic acid $\gamma$-lactone $(\mathrm{G})$ & 3 & $73,103,117,129,147,205,273,292,363,378$ & Lactones \\
\hline 67 & arabinoic acid $\gamma$-lactone (G) & 3 & $73,103,117,129,147,205,246,273,292$ & Lactones \\
\hline 68 & unknown VIII (G) & - & $73,147,191,217,278,407$ & Others \\
\hline 69 & unknown IX (G) & - & $73,103,133,147,221,278,291,407$ & Others \\
\hline 70 & unknown X (G) & - & $73,147,191,204,291,407$ & Others \\
\hline 71 & L-altrose & 5 & $73,147,191,205,217,305,319$ & Anhydrosugars \\
\hline 72 & 3,4,5-trihydroxy-6-(hydroxymethyl)tetrahydro-2H-pyran-2-one (G) & 4 & $73,103,117,129,147,189,205,217,220,243,305,333$ & Pyrans \\
\hline 73 & gluconic acid $\delta$-lactone & 4 & $73,103,117,129,147,189,205,217,230,244,305,333,361$ & Lactones \\
\hline 74 & glucopyranose $(\mathrm{G})$ & 5 & $73,103,117,129,147,191,204,217,231,246,273,363$ & Others \\
\hline
\end{tabular}

${ }^{a}$ Number of trimethylsilyl groups; $(\mathrm{G})$ : pyrolysis products only from glucose; $(\mathrm{C})$ : pyrolysis products only from cellulose 
As the pyrolysis time was increased, the pyrograms showed that the formation of lighter compounds was favoured, generating an increase in the heights of the peaks at lower retention times. These pyrolysis products are mainly molecules with two or three carbon atoms, different functionalities and unsaturations. In addition, some of these molecules are enols and they were not observed at short pyrolysis times. In fact, long pyrolysis times made it possible for HMDS to interact with enolizable carbonyls in their enolic forms. Once the hydroxyl group of an enol has been derivatised, the compound is blocked in this form and cannot regain its carbonyl moiety. This behaviour was best represented by the enolic form of hydroxyacetone (\#3). The peak of this species was absent at short retention times, but quickly increased at longer times and became one of the highest peaks in the pyrogram.

The peaks at intermediate retention times, on the contrary, were significantly reduced with the increase of pyrolysis time. These peaks were attributed to two main categories of pyrolysis products. The first category consists of rearrangement and multiple dehydration products such as cyclopentenones, pyrans and furans. The decrease in the formation of these molecules could be attributed to fragmentation reactions, generating the small molecules mentioned above. In fact, the literature reports that the elimination of water is the predominant initial reaction during the pyrolysis of glucose. Depending on the position of the $\mathrm{OH}$ involved in the process, several pyrolysis products can be obtained. Furans are produced when two $\mathrm{OH}$ on vicinal carbons are involved. Pyrans and cyclopentenones are also formed by similar reactions. The aldols formed as intermediates in these reactions can further undergo a retroaldol fragmentation, thus generating molecules such as hydroxyacetaldehyde (\#2) and hydroxyacetone $(\# 3)^{29}$. At long pyrolysis times the fragmentation of primary pyrolysis products into small molecules becomes a more important pyrolytic pathway compared to short pyrolysis times.

The second category of pyrolysis products, whose relative abundance was reduced at long pyrolysis times, was partially derivatised anhydrosugars. Anhydrosugars are produced with the formation of a C-O-C bridge between $\mathrm{C} 1$ and $\mathrm{C} 6$ or $\mathrm{C} 1$ and $\mathrm{C} 4$. These compounds are more resistant to fragmentation reactions ${ }^{33}$, and it is more likely that the increase in pyrolysis time favoured the derivatisation of all hydroxyl groups rather than a fragmentation. In fact, a remarkable increase in the relative abundance of the peaks corresponding to the persilylated forms of anhydrosugars (\#63, 64, 65) was obtained, and these became the highest peaks in the pyrogram.

At high retention times a cluster of compounds was detected in all pyrograms. The mass spectra suggested that these compounds are dimeric forms of glucose. It is known that addition, condensation and oligomerisation reactions can occur during pyrolysis. In particular, the recombination of monomers is possible due to the high density of radicals created in the pyrolytic process ${ }^{34}$. Although the straightforward identification of these dimeric species is particularly challenging and beyond the aim of this work, it was interesting to notice that the species formed were different for short and high pyrolysis times. Below 5 minutes of pyrolysis time, the mass spectra of most dimers showed peaks at $m / z, 217,361$ and 509. These $m / z$ values are reported in the literature as characteristic of the mass fragmentation of TMS derivatives of di-fructose dianhydrides obtained from fructose, inulin and sucrose ${ }^{35,36}$. These dianhy- drides, or compounds with similar structures, could also be formed from the pyrolysis of pure glucose in these conditions.

Starting from 10 minutes pyrolysis time, the chromatographic peaks present in the cluster showing the highest relative abundance changed. The mass spectra of the corresponding compounds showed the peak at $\mathrm{m} / \mathrm{z} 204$ being more abundant than the one at $\mathrm{m} / z$ 217. The peak at $\mathrm{m} / \mathrm{z} 204$ is assigned

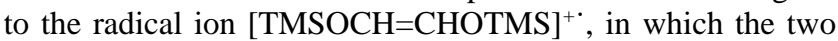
$\mathrm{OH}$ are on vicinal carbons, whereas the peak at $m / z, 217$ is assigned to the ion $[\mathrm{TMSOCH}=\mathrm{CH}-\mathrm{CHOTMS}]^{+}$, in which the two $\mathrm{OH}$ are separated by a methylene group ${ }^{20,37}$. The relative abundance of these fragment ions in the mass spectra can be indicative of the carbon atoms actually involved in the dimeric bonds ${ }^{38}$, even if straightforward conclusions are difficult to be obtained, due to the possibility of migration of functional groups during pyrolysis ${ }^{34}$. Peaks at $\mathrm{m} / \mathrm{z}, 407$ and 461 were also present in most of the mass spectra. Some of them also showed peaks at $m / z 508$ and 563, which are again reported for some isomeric forms of dianhydrides ${ }^{38}$. In addition to the formation of these different dimeric compounds for long pyrolysis time, their relative abundance also increased, showing that condensation reactions were more effective for long pyrolysis times.

Cellulose. Figure 2 reports the pyrograms obtained at 0.5 and 30 minutes pyrolysis time. Remarkable differences between the pyrograms at different times were obtained. Many of the pyrolysis products found for glucose were observed for cellulose as well, however the yields of each species at a given pyrolysis time varied considerably.

At short pyrolysis times, the highest peaks in the pyrogram of cellulose were attributed to multiple dehydration products, such as cyclopentenones (\#24, 29, 40, 41, 43, 50), aromatic compounds (\#51, 56) and pyranes (\#54, 62). The prevalence of this species using short reaction times is in agreement with the results that can be found using flash pyrolysis with in-situ derivatisation ${ }^{17}$. In particular, hydroxyacetic acid (\#7), 3hydroxy-2-hydroxymethyl-2-cyclopentenone (\#40), the enolic form of 2-hydroxycyclopenta-1,3-dione (\#41) and 2,3,5trihydroxy(4H)pyran-4-one (\#62) were the most abundant pyrolysis products in these conditions, confirming the results obtained by Fabbri et al. using the same derivatising agent ${ }^{17}$.

The formation of anhydrosugars appears to be less favoured in cellulose than in glucose. A comparison of these results with the literature is difficult. Differences in the yields of pyrolysis products between glucose and cellulose were investigated by TGA-FTIR and Py-GC/MS experiments, and were attributed to an involvement of the glycosidic bond in the reaction mechanisms ${ }^{39,40}$. Interestingly, these works provided opposite results, showing that cellulose is more prone than glucose to generate anhydrosugars. A role of the derivatising agent in the pyrolysis mechanisms is therefore to be hypothesised in our experiments.

It is not easy to compare the results obtained in different conditions, since cellulose crystallinity, distribution of oligomers, water content and pyrolysis temperature are all factors that can influence the yields of the different pyrolysis products ${ }^{8,41}$. In addition, the work by $\mathrm{Fu}$ et al. ${ }^{25}$ shows that the composition of the pyrolysate can vary significantly when using a sealed or an open vessel. Considering that the formation of levoglucosan from cellulose implicates a depolymerisation 
step by transglycosidation, it is evident from our results that, in these conditions, the chain scission with reverse aldolisation is a predominant pathway. This process, in fact, directly leads to the formation of smaller molecules.

At longer pyrolysis times an extensive fragmentation is observed. Small molecules, in fact, are the prevalent products at 30 minutes and above, and the highest peak in the pyrogram corresponds to the enolic form of hydroxyacetone (\#3). This behaviour could be correlated with the lower yield of anhydrosugars compared to glucose. In fact, as stated above, anhydrosugars are less prone to undergo fragmentations, whereas all the other pyrolysis products (furans, pyrans, cyclopentenones, etc.) can easily undergo further fragmentation, as the pyrolysis time increases. The increase in the formation of persilylated anhydrosugars for long pyrolysis times was however still observed in the pyrograms of cellulose.

At high retention times, a cluster of chromagraphic peaks assigned to dimeric compounds was observed in the pyrograms of cellulose. However, most of these compounds were different from those detected for glucose. Their mass spectra showed the peak at $\mathrm{m} / z 204$ as base peak rather than the one at $\mathrm{m} / z$ 217. Peaks at $\mathrm{m} / \mathrm{z}, 361$ and 407 were also present in most of the mass spectra. No peak at 509, typical of dianhydrides, was detected in these mass spectra. The dimeric species produced during the pyrolysis of cellulose were not condensation products, as dianhydrides are, but most likely they were the result of a not complete depolymerisation, followed by some rearrangements difficult to be predicted. It was also interesting to observe that for short pyrolysis times (up to 5 minutes) several dimeric compounds were formed, whereas for 10, 20, 30 and 60 minutes of pyrolysis one predominant dimer was observed (Figure 2b, labelled). The peak area for this dimer increases with pyrolysis time, indicating that, given enough time, all dimeric species rearrange to form one specific stable compound.

\section{Semi-quantitative calculations}

Distribution of categories of pyrolysis products. Once all peaks attributed to identified compounds were integrated, the areas were converted into percentages, considering the sum of all the compounds. The compounds were also grouped into categories, as listed in Table 1. A total percentage for each category was determined by addition of all percentage areas of its members. Figure 3 shows the results of these calculations for the six most relevant categories (small molecules, furans, pyrans, cyclopentenones, aromatics and anhydrosugars) at the different pyrolysis times.

In the case of glucose, anhydrosugars accounted for more than $50 \%$ at all pyrolysis times. They showed a slightly increasing trend, reaching more than $75 \%$ after 60 minutes. At short reaction times, all other compound categories accounted for less than $20 \%$ of the total composition, with small molecules and furans being the most abundant. At long reaction times, small molecules became the second predominant category, maintaining a yield of $c a .20 \%$ after 5 minutes. The yield of furans, on the other hand, decreased significantly and no furan derivative was detected after 60 minutes.

Different trends were observed for cellulose. At short reaction times, cyclopentenones were the most abundant products. At long reaction times, the yield of small molecules increased and those of cyclopentenones, furans and pyrans decreased. After 60 minutes, small molecules accounted for more than $50 \%$ of the total composition. Concerning anhydrosugars, it was interesting to note that, although their yield was as low as $5 \%$, this value was maintained throughout all the investigated time range. This is consistent with the observations made in the previous sections that the small molecules are mainly formed from secondary fragmentation reactions of cyclopentenones, furans and pyrans.

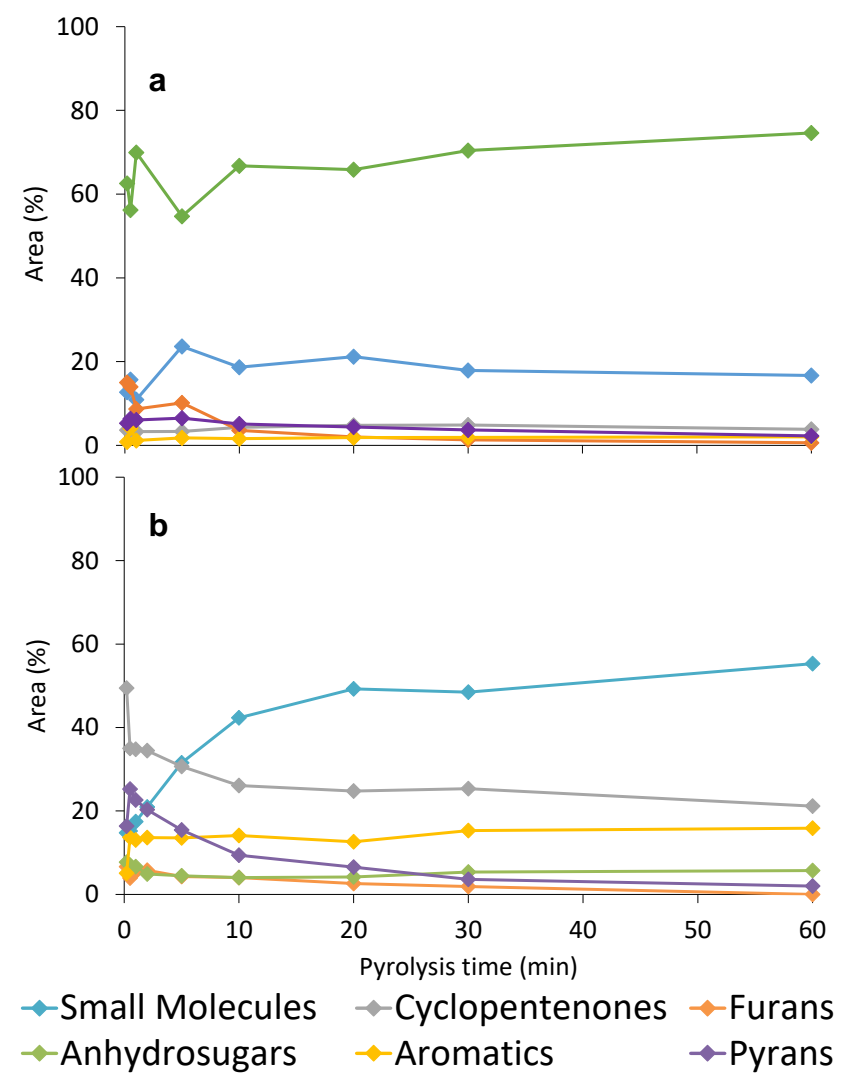

Figure 3. Product categories distribution at different pyrolysis times for a) glucose and b) cellulose.

Anhydrosugars. The dependence of the degree of derivatisation of anhydrosugars on the pyrolysis time for both glucose and cellulose was evaluated. For this analysis, the peak areas of the nine identified anhydrosugars (\#47, 48, 52, 53, 55, 57, $63,64,65)$ were considered and grouped according to their derivatisation degree (mono-TMS, di-TMS and tri-TMS). Integrated areas were then used to calculate the percentages of the three groups. The percentage values of mono-TMS, diTMS and tri-TMS anhydrosugars for both glucose and cellulose are showed in Figure 4, and some interesting differences between glucose and cellulose are worth mentioning.

At the shortest pyrolysis times $(0.2 \mathrm{~min})$, the presence of all three groups can be noted in both cases. For glucose, the mono-derivatised compounds accounted for a small percentage, but their signals were observed up to reaction times of more than 1 minute. On the other hand, the amount of monoderivatised anhydrosugars for cellulose was very high at 0.2 minutes, but their formation was not observed in any of the other pyrograms. 
A small percentage of partially derivatised compounds was still present up to 30 minutes for glucose, whereas at this time only tri-derivatised compounds could be observed in the cellulose pyrogram. At 60 minutes, the longest observed pyrolysis time, both glucose and cellulose achieved a complete persilylation of the anhydrosugars.

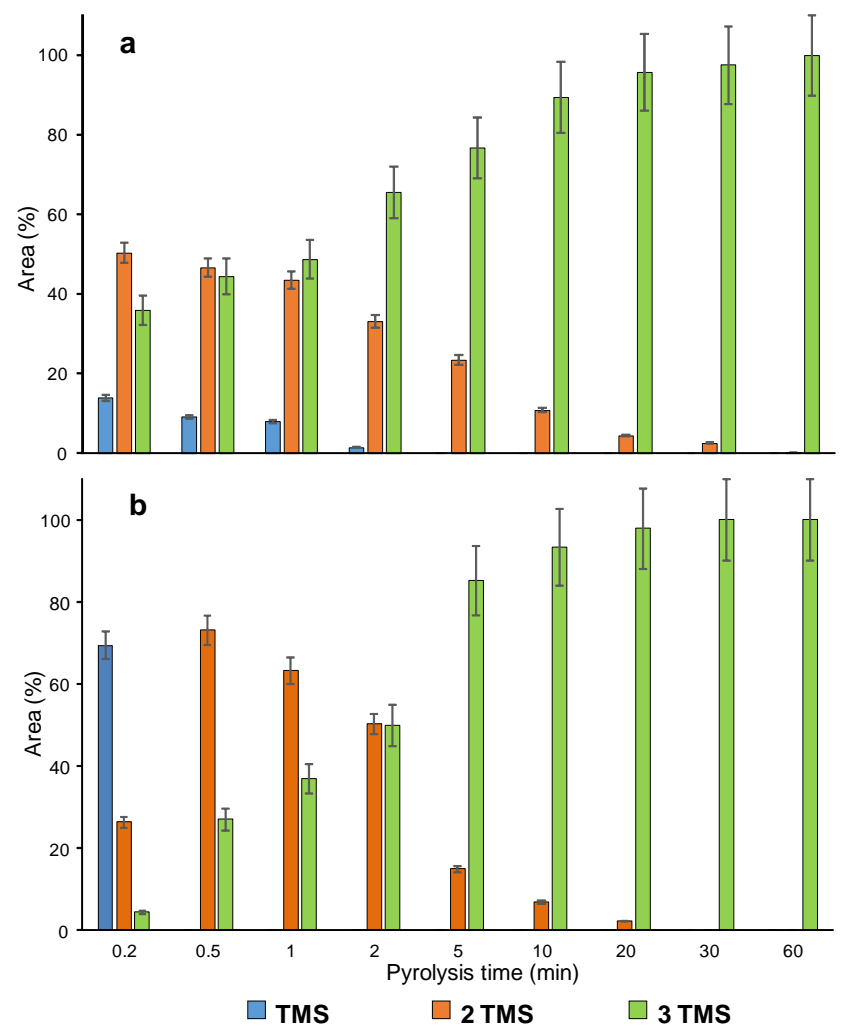

Figure 4. Percentage chromatographic areas of mono-, diand tri-trimethylsilylated anhydrosugars formed at different pyrolysis times for a) glucose and b) cellulose.

\section{CONCLUSIONS}

The effect of pyrolysis time for glucose and cellulose in the presence of HMDS was evaluated in the range $0.2-60$ minutes using an on-line micro reaction sampler. Replicas of the same experiments gave relative standard deviations not higher than $10 \%$, allowing semi-quantitative calculations to be carried out.

At short reaction times, the results are similar to those obtained with a conventional flash pyrolysis in the presence of the derivatising agent. The dominant reaction for glucose was the loss of a water molecule leading to the formation of levoglucosan. The depolymerisation step in cellulose pyrolysis, on the other hand, favoured the formation of cyclopentenones, pyrans and furans. When the reaction time was increased, a significantly different behaviour was observed for glucose and cellulose, due to the different distribution of the pyrolysis products. An increase in the average derivatisation degree of anhydrosugars was observed, and a complete persilylation was obtained in both cases at 60 minutes. While levoglucosan proved stable at the pyrolysis temperature even at long reaction times, cyclopentenones, pyrans and furans underwent secondary reactions, generating small (C1-C3) mole- cules. In addition, long reaction times ( $\geq 10$ minutes) favoured the silylation of carbonyl functionalities in their enolic form.

A cluster of peaks was observed for both glucose and cellulose at long retention times. In the case of glucose, the peaks were attributed to di-fructose dianhydrides, possibly originating from condensation reactions between two monosaccharide molecules. The average intensity of the cluster increased at long pyrolysis times. In the case of cellulose, on the other hand, the peaks were attributed to dimers deriving from an incomplete depolymerisation. The increase in pyrolysis time reduced the number of peaks of the cluster, showing that a preferred species was obtained by rearrangement reactions of the other dimers.

The persilylation of anhydrosugars and the formation of small molecules both contributed to a simplification of the pyrograms at long reaction times, with the peaks attributed to the most stable species growing significantly in intensity. The increase in sensitivity and chromatographic resolution proves very useful when dealing with mixtures or non-standard samples, and reduces the error of semi-quantitative calculations. In addition, given the current focus on pyrolysis as promising tool able of converting biomass into bio-fuels and value-added chemicals, our data could promote new investigations and research for acquiring a more comprehensive picture of the chemical pathways undergone by carbohydrates during thermal conversion treatments.

\section{REFERENCES}

(1) Kačík, F.; Podzimek, Š.; Vizárová, K.; Kačíková, D.; Čabalová, I. Cellulose 2016, 23, 357-366.

(2) C.S, J. C.; George, N.; Narayanankutty, S. K. Carbohydr. Polym. 2016, 142, 158-166.

(3) Park, S.; Baker, J.; Himmel, M.; Parilla, P.; Johnson, D. Biotechnol. Biofuels 2010, 3, 1-10.

(4) Schwanninger, M.; Rodrigues, J.; Fackler, K. J. Near Infrared Spectrosc. 2011, 19, 287-308.

(5) Bardet, M.; Gerbaud, G.; Giffard, M.; Doan, C.; Hediger, S.; Le Pape, L. Prog. Nucl. Magn. Reson. Spectrosc. 2009, 55, 199-214.

(6) Newman, R. H. Solid State Nucl. Magn. Reson. 1999, 15, 21-29.

(7) Santoni, I.; Callone, E.; Sandak, A.; Sandak, J.; Dirè, S. Carbohydr. Polym. 2015, 117, 710-721.

(8) Moldoveanu, S. C. In Analytical Pyrolysis of Natural Organic Polymers, Coleman, D.; Price, B. F., Eds.; Elsevier Science: Amsterdam, 1998, pp 217-316.

(9) Pouwels, A. D.; Eijkel, G. B.; Boon, J. J. J. Anal. Appl. Pyrolysis 1989, 14, 237-280.

(10) Shafizadeh, F.; Fu, Y. L. Carbohydr. Res. 1973, 29, $113-$ 122.

(11) Conley, R. T. In Thermal stability of plymers, Dekker, M., Ed.: New York, 1970.

(12) Wampler, T. P. In Applied Pyrolysis handbook, Wampler, T. P., Ed.; CRC Press: Boca Raton, 2007, pp 1-26. (13) Kim, P.; Rials, T. G.; Labbé, N.; Chmely, S. C. Energy Fuels 2016, 30, 3167-3174.

(14) Qiang, L.; Wen-Zhi, L.; Dong, Z.; Xi-Feng, Z. J. Anal. Appl. Pyrolysis 2009, 84, 131-138. 
(15) Adam, J.; Blazso, M.; Meszaros, E.; Stöcker, M.; Nilsen, M. H.; Bouzga, A.; Hustad, J. E.; Grønli, M.; Øye, G. Fuel 2005, 84, 1494-1502.

(16) Challinor, J. M. J. Anal. Appl. Pyrolysis 2001, 61, 3-34.

(17) Fabbri, D.; Chiavari, G. Anal. Chim. Acta 2001, 449, 271-280.

(18) Fabbri, D.; Helleur, R. J. Anal. Appl. Pyrolysis 1999, 49, 277-293

(19) Fabbri, D.; Prati, S.; Vassura, I.; Chiavari, G. J. Anal. Appl. Pyrolysis 2003, 68-69, 163-171.

(20) Fabbri, D.; Chiavari, G.; Prati, S.; Vassura, I.; Vangelista, M. Rapid Commun. Mass Spectrom. 2002, 16, 2349 - 2355.

(21) Tamburini, D.; Łucejko, J. J.; Zborowska, M.; Modugno, F.; Prądzyński, W.; Colombini, M. P. J. Anal. Appl. Pyrolysis 2015, 115, 7-15.

(22) Łucejko, J. J.; Modugno, F.; Ribechini, E.; Tamburini, D.; Colombini, M. P. Applied Spectroscopy Reviews 2015, 50, 584-625.

(23) Ribechini, E.; Zanaboni, M.; Galletti, A. M. R.; Antonetti, C.; o Di Nasso, N. N.; Bonari, E.; Colombini, M. P. J. Anal. Appl. Pyrolysis 2012, 94, 223-229.

(24) Hosaka, A.; Watanabe, C.; Teramae, N.; Ohtani, H. J.

Anal. Appl. Pyrolysis 2014, 106, 160-163.

(25) Fu, Y.; Kato, K.; Ohtani, H.; Chen, Y. J. Wood Chem.

Technol. 2014, 34, 1-7.

(26) Galletti, G. C.; Bocchini, P. Rapid Commun. Mass Spectrom. 1995, 9, 815-826.

(27) Ralph, J.; Hatfield, R. D. J. Agric. Food Chem. 1991, 39, 1426-1437.
(28) Braovac, S.; Tamburini, D.; Łucejko, J. J.; McQueen, C.; Kutzke, H.; Colombini, M. P. Microchem. J. 2016, 124, 368379.

(29) Moldoveanu, S. C. Pyrolysis of organic molecules: applications to health and environmental issues; Elsevier, 2009;

Vol. 28.

(30) Paine III, J. B.; Pithawalla, Y. B.; Naworal, J. D. J. Anal. Appl. Pyrolysis 2008, 82, 10-41.

(31) Paine III, J. B.; Pithawalla, Y. B.; Naworal, J. D. J. Anal. Appl. Pyrolysis 2008, 82, 42-69.

(32) Paine III, J. B.; Pithawalla, Y. B.; Naworal, J. D. J. Anal. Appl. Pyrolysis 2008, 83, 37-63.

(33) Patwardhan, P. R.; Satrio, J. A.; Brown, R. C.; Shanks, B. H. J. Anal. Appl. Pyrolysis 2009, 86, 323-330.

(34) Moldoveanu, S. C. Analytical Pyrolysis of Natural Organic Polymers; Elsevier Science: Amsterdam, 1998; Vol. 20. (35) Manley-Harris M., R. G. N. Carbohydr. Res. 1992, 226.

(36) Manley-Harris M., R. G. N. Carbohydr. Res. 1996, 287. (37) Bleton, J.; Mejanelle, P.; Sansoulet, J.; Goursaud, S.; Tchapla, A. J. Chromatogr. A 1996, 720, 27-49.

(38) Blize A.E., M.-H. M., Richards G.N. Carbohydr. Res. 1994, 265

(39) Wu, S.; Shen, D.; Hu, J.; Zhang, H.; Xiao, R. J. Anal. Appl. Pyrolysis 2016.

(40) Mettler, M. S.; Paulsen, A. D.; Vlachos, D. G.; Dauenhauer, P. J. Green Chem. 2012, 14, 1284-1288.

(41) Lu, Q.; Yang, X.-c.; Dong, C.-q.; Zhang, Z.-f.; Zhang, X.m.; Zhu, X.-f. J. Anal. Appl. Pyrolysis 2011, 92, 430-438.

\section{AUTHOR INFORMATION}

\section{Corresponding Author}

* Corresponding author: Erika Ribechini. e-mail: erika.ribechini@unipi.it, tel: +390502219312

\section{Present Addresses}

Dr. Diego Tamburini currently works at the Department of Scientific Research, The British Museum, Great Russell Street, London WC1B 3DG

\section{Author Contributions}

The manuscript was written through contributions of all authors. All authors have given approval to the final version of the manuscript.

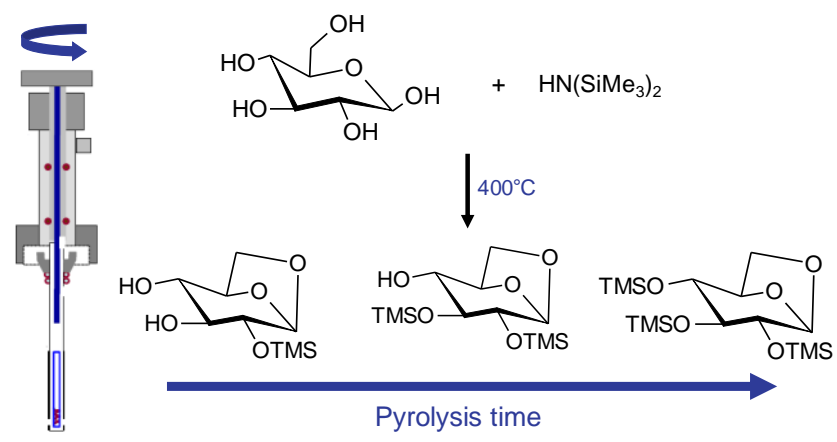

